This is a postprint version of the following published document:

Alvaredo, P.; Roa, J. J.; Jiménez-Pique, E.; Llanes, L.; Gordo, E. (2016). Characterization of interfaces between TiCN and iron-base binders. International Journal of Refractory Metals and Hard Materials. DOI: $10.1016 /$ j.ijrmhm.2016.08.010

(C) Elsevier 2016

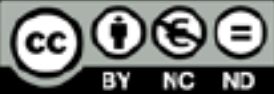

This work is licensed under a Creative Commons Attribution-NonCommercialNoDerivatives 4.0 International License. 


\title{
Characterization of interfaces between TiCN and iron-base binders
}

\author{
P. Alvaredo ${ }^{1}$, J.J. Roa ${ }^{2,3}$, E. Jiménez-Pique ${ }^{2,3}$, L. Llanes ${ }^{2,3}$, E. Gordo ${ }^{1}$ \\ ${ }^{1}$ Department of Materials Science and Engineering, IMAAB. University Carlos III of Madrid, \\ Avda. Universidad, 30, 28911 Leganés, Madrid, Spain \\ ${ }^{2}$ Department of Materials Science and Engineering, CIEFMA. Polytechnic University of \\ Catalonia, Avda. Diagonal 647, 08028 Barcelona, Spain. \\ ${ }^{3} \mathrm{CRnE}$, Campus Diagonal Sud, Edificio C', Polytechnic University of Catalonia, C/ Pascual i Vila \\ 15, 08028 Barcelona, Spain.
}

\begin{abstract}
This work includes a study of the interface between matrix and reinforcement in $\mathrm{Fe}-\mathrm{Ti}(\mathrm{C}, \mathrm{N})$ systems. A study of wettability and solubility between metal and ceramic phases is first performed. It combines wetting experiments at high temperature with kinetics simulation. In doing so, dense $\mathrm{Ti}(\mathrm{C}, \mathrm{N})$ is produced by spark plasma sintering and used as substrate. On the other hand, $\mathrm{Fe}, \mathrm{Fe}-\mathrm{WC}$ and $\mathrm{Fe}-\mathrm{Mo}_{2} \mathrm{C}$ alloys are used as metal matrix to evaluate the influence of $\mathrm{WC}$ and $\mathrm{Mo}_{2} \mathrm{C}$ carbides on the formation, composition and properties of the interface. These experiments are complemented by a micromechanical study of the interface. Hardness and elastic modulus are obtained from analysis of nanoindentation arrays in the matrix and into the reinforcement for each system. The sliding contact response at the interface (and neighboring regions) is evaluated by cross-section nanoscratches conducted at different load levels.
\end{abstract}




\section{Introduction}

Several studies have been conducted on a TiCN-based cermet with a high speed steel as metallic matrix. Results obtained show high values of hardness and toughness [1], as well as good oxidation response at high temperature and wear resistance [2,3]. Main reasons for choosing a $\mathrm{Fe}$ alloy to replace the conventional $\mathrm{Ni}$ and $\mathrm{Co}$ used as metallic matrix in this type of composites are its lower price and toxicity, in addition to the possibility to adapt its properties to intended applications by means of heat treatment. A commercial high speed steel has been chosen because it contains alloying elements such as $W$ and Mo, known to be carbides formers. Furthermore, the presence of carbides of transition elements in cermets not only increases the proportion of hard phase of the composite material but also improves the sinterability of them because they play a key role in the solubility between matrix and reinforcement.

The processing of TiCN-based cermets is performed by Liquid Phase Sintering (LPS) and leads to the typical core-rim microstructure of $\mathrm{Ti}(\mathrm{C}, \mathrm{N})$-based cermets. This microstructure is formed during the sintering, where solid ceramic grains coexist with the liquid metal. As a result, $\mathrm{Ti}(\mathrm{C}, \mathrm{N})$ particles are first wetted and partially dissolved by the liquid, but later precipitate again enriched in transition elements from the secondary refractory carbides. The terms core and rim correspond with undissolved $\mathrm{Ti}(\mathrm{C}, \mathrm{N})$ and solid solution $(\mathrm{Ti}, \mathrm{M})(\mathrm{C}, \mathrm{N})$ respectively, being $M$ the transition metal from the refractory carbides as $\mathrm{WC}$ and $\mathrm{Mo}_{2} \mathrm{C}$. The presence of this rim strongly affects the mechanical properties of the cermet. Its formation, composition and thickness depend on the solubility of the reinforcement particles on the liquid metal and the mechanisms taking place during sintering [4-6].

The solubility processes during sintering strongly affect the formation of the interface between metallic and ceramic phases. They are also critical for developing the final microstructure and properties of the cermet. Within this context, this work presents an investigation of the interface of cermet systems where Fe-base matrices coexist with $\mathrm{Ti}(\mathrm{C}, \mathrm{N})$ reinforcements. A study of wettability and solubility between metal and ceramic phases is first performed. It combines wetting experiments at high temperature with kinetics simulation. In doing so, dense $\operatorname{Ti}(\mathrm{C}, \mathrm{N})$ was produced by spark plasma sintering (SPS) and used as substrate. On the other hand, Fe, $\mathrm{Fe}-\mathrm{WC}$ and $\mathrm{Fe}-\mathrm{Mo}_{2} \mathrm{C}$ alloys were used as metal matrix to evaluate the influence of WC and $\mathrm{Mo}_{2} \mathrm{C}$ carbides added to the $\mathrm{Fe}$ matrix on the formation, composition and micromechanical properties of the interface. Hardness and elastic modulus have been obtained by using the nanoindentation technique in a region near the interface for each system. Finally, the sliding contact response close to and at the interface has been evaluated by cross-section nanoscratches, from the matrix into the reinforcement, carried out at different load levels.

\section{Materials and methodology}

The powders used as starting materials in this work are: $\mathrm{TiC}_{0.5} \mathrm{~N}_{0.5}(\mathrm{H}$. C. Starck, D50 $=3.7$ $\mu \mathrm{m})$ ), Fe (Ecka granules, D50 = $7.9 \mu \mathrm{m}$ ), WC (Alfa Aesar), Mo (Aldrich) and graphite. To study the influence of $\mathrm{WC}$ and $\mathrm{Mo}_{2} \mathrm{C}$, the compositions studied correspond with carbide amounts in high speed steel M2 (6.2 wt. \% W; 4.8 wt. \% Mo; 4.1 wt. \% Cr; 1.8 wt. \% V; 0.8 wt. \% C) used in previous works [1,3]. Therefore the compositions of the metallic samples studied are $\mathrm{Fe}, \mathrm{Fe}-$ 6.6WC and $\mathrm{Fe}-5.1 \mathrm{Mo}_{2} \mathrm{C}$.

The simulation of high temperature solubility at the interface between the liquid metal sample ( $\mathrm{Fe}, \mathrm{Fe}-6.6 \mathrm{WC}$ and $\mathrm{Fe}-5.1 \mathrm{Mo}_{2} \mathrm{C}$ ) and $\mathrm{TiCN}$ solid substrate is performed by using the software Dictra with the TCFE7 database [7]. The design of the system used in the simulation is shown in Figure 1. There are two regions: a left one corresponding with the liquid metal sample and a right one corresponding with the TiCN solid substrate. The simulated distance is around $100 \mu \mathrm{m}$ and the simulation times are: $1,10,100$ and $1000 \mathrm{~s}$. The temperature at which simulation has been performed is $1560{ }^{\circ} \mathrm{C}$, in order to have the metallic sample in liquid state. In the case of $\mathrm{Fe}$ sample, it is always in liquid state at $1560{ }^{\circ} \mathrm{C}$, because the melting point of $\mathrm{Fe}$ is $1538^{\circ} \mathrm{C}$. In the others systems, the binary phase diagram of $\mathrm{Fe}-6.6 \mathrm{WC}$ and $\mathrm{Fe}-5.1 \mathrm{Mo}_{2} \mathrm{C}$ calculated by Thermocalc software [7] (Figure 2), confirms that these two compositions are in liquid state at the simulation temperature. Calculations are based on the free Gibbs energy minimization code 
and mass conversion rule in combination with TCFE7 database (Scientific Group Thermodata Europe).

Figure 1. Scheme of the system designed for the simulation of the diffusion (at the interface) between the liquid metallic sample and the solid ceramic substrate.

Figure 2. Binary phase diagrams of Fe-WC (left) and $\mathrm{Fe}-\mathrm{Mo}_{2} \mathrm{C}$ (right), calculated by Thermocalc software.

Aiming to assess the wettability of metal samples on ceramic substrates, wetting experiments at high temperature have been performed. They were conducted in a tubular furnace under $\mathrm{Ar}$ atmosphere. A camera is externally adapted to the furnace, to record the evolution of the shape of the drop of liquid metal on the substrate. The scheme of the equipment is shown in Figure 3. The evolution of the contact angle between the two phases as a function of the residence time and temperature is monitored by the sessile drop method [8].

Figure 3. Scheme of the high temperature contact angle measurement equipment.

The metallic samples were previously sintered under vacuum atmosphere at $1450{ }^{\circ} \mathrm{C}$ during 1 hour. The TiCN substrates were sintered by SPS at $1900^{\circ} \mathrm{C}$ and a pressure of $70 \mathrm{MPa}$ with a heating and cooling rate of $100{ }^{\circ} \mathrm{C} / \mathrm{min}$. Final relative density was $99.5 \%$.

After the wetting experiments, samples were mounted, transversally cut, ground and polished until mirror polish condition. The resulting cross section between metal sample and ceramic substrate was observed by Scanning Electron Microscope (SEM) and analyzed by energy dispersive X-ray spectroscopy (EDX).

Prior to micromechanical characterization, the specimens were re-polished with colloidal silica, in an ordinary metallographic polisher. The quality of the finishing was checked by confocal laser scanning microscopy (CLSM, LEXT OLS3100) in order to avoid the presence of scratches on the surface prior to testing. After that, the surface to be tested was cleaned using a non-ionic surfactant (detergent) and afterwards dried with pure air.

The micromechanical properties evaluated in cross section were conducted in the substrate as well as in the coating region for each system included the evaluation of their hardness $(H)$ and elastic modulus $(E)$ through Nanoindentation technique. It was performed using a nanoindenter XP (MTS) equipped with a continuous stiffness measurement (CSM) modulus, the latter allowing a dynamic determination of hardness and elastic modulus during the indentation [9]. Indentations were organized in a homogeneous spaced array of 16 indentations (4 by 4 ) at $1000 \mathrm{~nm}$ of maximum displacement into surface. Indentation array was located in a region near the interface with a constant distance between each residual imprint of $50 \mu \mathrm{m}$ in order to avoid any overlapping effect. Strain rate through was kept constant at $0.05 \mathrm{~s}^{-1}$ during the nanoindentation test. The indenter shape was carefully calibrated by indenting standard sample of known Young's modulus (Fused Silica, $72 \mathrm{GPa}$ ). The hardness and elastic modulus were determined by using the Oliver and Pharr method [10], assuming a constant Poisson ratio for the specimens equals to 0.3 .

Sliding contact tests were done at micrometric length scale by using the nanoindenter system referred above. A Berkovich indenter was employed to scratch the interfaces from the TiCN substrate into the reinforcement. A Berkovich indenter was employed to scratch the interface at incremental (from 0 up to $100 \mathrm{mN}$ ) and constant applied load $(100 \mathrm{mN})$, at a constant scratch velocity of $10 \mu \mathrm{m} / \mathrm{s}$. Three different scans were done in each sample with a scratch length of $200 \mu \mathrm{m}$ and in an interval between them of the same length of the scratch. More information about the sliding method is available in Ref. [11].

Surface damage associated with residual nanoindentation imprints and nanoscratchs were visualized by field emission scanning electron microscope (FESEM, JEOL-7100F) at $20 \mathrm{kV}$.

\section{Results}

Figure 4 shows the evolution of the contact angle of the systems Fe/TiCN, Fe-6.6WC/TiCN and $\mathrm{Fe}-5.1 \mathrm{Mo}_{2} \mathrm{C} / \mathrm{TiCN}$ as a function of the residence time. The results are shown such that $t=0 \mathrm{~s}$ corresponds to the instant where formation of the liquid phase of the metallic sample is first 
observed. It is seen that liquid Fe does not wet the TiCN substrate. It forms a $100^{\circ}$ contact angle which does not change with time. On the other hand, Fe-6.6WC and $5.1 \mathrm{Mo}_{2} \mathrm{C}$ exhibits a clearly improved wettability behavior on the TiCN substrate. Contact angle for these systems is always lower than $100^{\circ}$, yielding final values of $70^{\circ}$ and $38^{\circ}$ for $\mathrm{Fe}-6.6 \mathrm{WC}$ and $5.1 \mathrm{Mo}_{2} \mathrm{C}$, respectively.

Figure 4. Evolution of contact angle regarding time of the metal/substrate systems: Fe/TiCN; Fe6.2WC/TiCN and $\mathrm{Fe}-5.1 \mathrm{Mo}_{2} \mathrm{C} / \mathrm{TiCN}$.

Figure 5 shows the interfaces of the systems - Fe/TiCN, Fe-6.6WC/TiCN and Fe-5.1Mo 2 C/TiCN - formed after the wetting experiments, as well as the composition analysis of the interfaces. The diffusion simulation, performed by Dictra, allows to understand their interaction at high temperature and to explain the differences found in the wetting behavior. The diffusion of $\mathrm{C}$ and $\mathrm{N}$, and $\mathrm{W}$ and Mo, as simulated by Dictra, is shown in Figure 6 and Figure 7.

For the Fe/TiCN system, it is observed that the substrate is not dissolved by the Fe sample. However, it is observed the diffusion of $\mathrm{C}$ into the Fe sample. Such diffusion is also evidenced in Figure 6 in which the percentage of $\mathrm{N}$ is increased and the percentage of $\mathrm{C}$ is decreased at the interface. This behavior occurs because the $\mathrm{TiC}_{0.5} \mathrm{~N}_{0.5}$ has changed to TiN and TiC is already dissolved into Fe sample due to the much higher solubilty of $\mathrm{TiC}$ in Fe than $\mathrm{TiN}$ in $\mathrm{Fe}$ [12]. For the system $(\mathrm{Fe}+6.2 \mathrm{WC}) / \mathrm{TiCN}$, a clear dissolution of the TiCN substrate is evidenced at the interface. EDX analysis through the interface reveals two features: (i) reduction of $\mathrm{C}$ wt. \% content with respect to the substrate composition, and (ii) a diffusion mechanism due to the presence of $\mathrm{W}$ element. Both effects are also observed in the Dictra results presented in Figure 6 and 7, respectively. The analysis of the interface could indicate the formation of a $(\mathrm{Ti}, \mathrm{W})(\mathrm{C}$, $\mathrm{N})$ solid solution, which is characteristic of the rim phase in cermets. The interface of the system $\left(\mathrm{Fe}+5.1 \mathrm{Mo}_{2} \mathrm{C}\right) / \mathrm{TiCN}$ also shows a relative high solubility of the TiCN substrate on the alloy sample. EDX analysis shows the reduction of the $\mathrm{C}$ wt. \% content and the presence of Mo, which is observed in the results obtained by doing simulation and represented in Figure 7 . This analysis highlights the formation of the $(\mathrm{Ti}, \mathrm{Mo})(\mathrm{C}, \mathrm{N})$ solid solution.

Samples with WC and $\mathrm{Mo}_{2} \mathrm{C}$ present a slightly better wettability on TiCN substrate, as compared to that exhibited by the Fe sample. This effect may be attributed to several factors: (i) an increase of the solubility of TiCN in the liquid alloy, and/or (ii) a change in the composition of the phases which allows a reduction of the contact angle improving the spreading of the liquid phase on the TiCN substrate.

Figure 5. Interface of the systems (left side): Fe/TiCN; Fe-6.2WC/TiCN and Fe-4.8Mo $2 \mathrm{C} / \mathrm{TiCN}$ after wetting experiments and EDX analysis of metallic sample, interface and TiCN substrate (right side). (All the compositions are expressed in wt. \%).

Figure 6. Evolution of the $\mathrm{C}$ and $\mathrm{N}$ wt. \% at the interface for the systems Fe/TiCN; Fe-6.6WC/TiCN and Fe$5.1 \mathrm{Mo}_{2} \mathrm{C} / \mathrm{TiCN}$ simulated by Dictra software (at $1560{ }^{\circ} \mathrm{C}$ in a distance of $100 \mu \mathrm{m}$ during $300 \mathrm{~s}$ ).

Figure 7. Evolution of the $\mathrm{W}$ and $\mathrm{Mo}$ wt. \% at the interface of the systems Fe-6.6WC/TiCN and Fe$5.1 \mathrm{Mo}_{2} \mathrm{C} / \mathrm{TiCN}$, respectively, simulated by Dictra software (at $1560{ }^{\circ} \mathrm{C}$ in a distance of $100 \mu \mathrm{m}$ during 300 s).

The improvement on the wettability by the addition of $\mathrm{W}$ and Mo carbides would be reflected in an improvement on the sinterability of the cermet getting higher densification during LPS. Additionally, the increasing of the TiCN solubility and the formation of the $(\mathrm{Ti}, \mathrm{M})(\mathrm{C}, \mathrm{N})$ solid solution would lead to a smaller grain growth and agglomeration of the reinforcement particles. Beside these mentioned changes, the presence of $\mathrm{W}$ and Mo carbides could be expected to affects the mechanical properties of the material and the adhesive strength of matrix and reinforcement at the interface.

The micromechanical properties, in terms of hardness as a function of the maximum displacement into surface, for each liquid metal sample as well as for the TiCN substrate are shown in Figure 8. Hardness is nearly constant for displacements into the surface inside the interval $100-1000 \mathrm{~nm}$. For lower penetrations, changes in hardness are extremely complicated to estimate due to several factors: (i) the influence of the superficial defects (i.e. roughness, residual stresses, among others), and (ii) the bluntness of the Berkovich tip indenter. Therefore, unless otherwise stated, the indentation hardness presented in Table 1 is referred to this displacement interval. 
The elastic modulus values reported in Table 1 have been determined at $200 \mathrm{~nm}$, where this property is constant, due to negligible interaction of the elastic field with the interface. As it can be appreciated in this table, the elastic modulus for the liquid metal sample is around $205 \mathrm{GPa}$. On the other hand, the TiCN substrate is slightly stiffer, yielding a value of $350 \mathrm{GPa}$.

As it is shown in Table 1, hardness values for the reinforcement range between 2 and 9 GPa for the $\mathrm{Fe}$ and $\mathrm{Fe}-\mathrm{Mo}_{2} \mathrm{C}$ systems, respectively. Meanwhile, for the Fe-WC system, hardness values are closer to those obtained for the Fe system. This trend can be attributed to two different factors: differences on intrinsic hardness and/or on density for the reinforcement particles (WC and/or $\mathrm{Mo}_{2} \mathrm{C}$ ). As it was reported by Nino and co-workers, at low applied loads the Vickers' hardness for both systems is around $20 \mathrm{GPa}$ [13]. Then, differences determined for the Fe-WC and the $\mathrm{Fe}-\mathrm{Mo}_{2} \mathrm{C}$ systems should be related to microstructural assemblage differences in terms of density. Then, this parameter will govern the amount of particles heterogeneously distributed as reinforcement. Considering that density of $\mathrm{Mo}_{2} \mathrm{C}$ is about half that of WC $\left(15.7\right.$ and $8.9 \mathrm{~g} / \mathrm{cm}^{3}$ for $\mathrm{WC}$ and $\mathrm{Mo}_{2} \mathrm{C}$ respectively), relative amount of $\mathrm{Mo}_{2} \mathrm{C}$ may be expected to be much higher than that of WC. Accordingly, measured hardness values are also higher for $\mathrm{Fe}-\mathrm{Mo}_{2} \mathrm{C}$ system than for the Fe-WC one.

Table 1. Hardness (determined from the hardness average for the displacement interval ranged between $100-1000 \mathrm{~nm}$ ) and elastic modulus (at $200 \mathrm{~nm}$ ) for the TiCN substrate and each metal liquid sample.

Figure 8. Hardness evolution for all the systems of study against the maximum displacement into surface.

Figure 9 exhibits images obtained by FESEM for $\mathrm{Fe}$ and $\mathrm{Fe}-\mathrm{Mo}_{2} \mathrm{C}$ liquid metal specimens. As seen in these images, the Fe imprint present a pile-up effect surrounding the residual indentation (see white arrows) due to their ductile behavior. On the other hand, the imprint done in the $\mathrm{Fe}-\mathrm{Mo}_{2} \mathrm{C}$ system does not present this effect, pointing out that this metal system is harder than the $\mathrm{Fe}$ system. No microcracks generated during the indentation process can be appreciated either. These observations are in agreement with the data presented in Figure 8 and summarized in Table 1 for both systems.

Figure 9. FESEM image of a residual imprint performed at $1000 \mathrm{~nm}$ of maximum displacement into surface for $\mathrm{Fe}$ and $\mathrm{Fe}-\mathrm{MO}_{2} \mathrm{C}$ metallic systems.

In the scratch test there is a large shear stress on the surface caused by friction between the material and the indenter. Figure 10 shows an entire scratch track for the Fe/TiCN system passing through the interface (left hand side) for an incremental load experiment (from 0 up to $100 \mathrm{mN}$ of maximum sliding load). In the right hand side of this image, it is possible to appreciate a magnification from the top-view FESEM of nanoscratches tracks for each system investigated here at constant load $(\sim 100 \mathrm{mN})$. As it can be depicted in this image, damage events, location of damage features changes from the metallic into the ceramic phase when comparing the Fe/TiCN system with the other two systems (Fe-6.2WC/TiCN and Fe$5.1 \mathrm{Mo}_{2} \mathrm{C} / \mathrm{TiCN}$ ). However, in all the cases damage may be defined as cohesive (although close to the interface) and not adhesive, pointing out satisfactory levels of adhesion strength for the three systems studied. This is particularly true for the $\mathrm{Fe}-\mathrm{Mo}_{2} \mathrm{C} / \mathrm{TiCN}$ where mechanical integrity at the interface is neatly observed. The transition on the location of the damage features, as referred above, is here captured because nanoscratch testing was conducted from the matrix into the reinforcement, and should be related to the gradual changes in chemical composition, and consequent hardness and brittleness increase, present in the vicinity of the interface for Fe$6.2 \mathrm{WC} / \mathrm{TiCN}$ and $\mathrm{Fe}-5.1 \mathrm{Mo}_{2} \mathrm{C} / \mathrm{TiCN}$ systems. Similar damage scenario was observed for the sliding tests done at incremental load $(0$ to $100 \mathrm{mN})$; thus, they are not presented again. It means that fracture events induced under sliding conditions do not depend on the applied stress, but rather on the chemical and microstructural nature of regions neighboring the interface.

Figure 10. FESEM image for the nanoscratch track performed at incremental load from 0 to $100 \mathrm{mN}$ (left hand side) for the Fe/TiCN system. Magnification of the main fracture events activated in the interface for all the systems investigated here done at constant load $(100 \mathrm{mN})$. 


\section{Conclusions}

Chemically and mechanical interface characterization of iron-matrix cermets was studied by considering three different systems: $\mathrm{Fe} / \mathrm{TiCN}$; $\mathrm{Fe}-\mathrm{WC} / \mathrm{TiCN}$ and $\mathrm{Fe}-\mathrm{Mo}_{2} \mathrm{C} / \mathrm{TiCN}$. The main conclusions resulting from the study can be summarized as follows:

i) Carbide additions results in an enhanced wetting behavior, possibly as a result of a simple change of the interface composition. It would either modify the surface energy between solid and liquid phases, decreasing the contact angle; or increase the substrate solubility on the metallic sample, leading then to a higher dissolution of the substrate and a better spreading of the liquid sample.

ii) The TiCN substrate is harder and stiffer than the alloys evaluated here. As Fe-base matrices include WC and Mo2C contents, an increase of both properties is attained, as compared to pure Fe reinforcement.

iii) Nanoscratch testing (using a sharp indenter tip) results in a change in the location of damage events, from the ceramic to the metallic phase, when comparing the Fe-TiCN systems with the $\mathrm{Fe}-\mathrm{WC} / \mathrm{TiCN}$ and $\mathrm{Fe}-\mathrm{Mo}_{2} \mathrm{C} / \mathrm{TiCN}$ ones. However, in all the cases damage discerned is rather cohesive and not adhesive, this being quite clear for the $\mathrm{Fe}-$ $\mathrm{Mo}_{2} \mathrm{C} / \mathrm{TiCN}$ system. Such a response is related to the gradual chemical composition changes (and consequent hardness and brittleness increase) in regions close to the interface.

iv) Damage scenarios induced during the sliding tests are independent of the stress stare associated with sliding contact loads.

\section{Acknowledgements}

The authors would like to acknowledge the financial support from the Spanish Government through the project MAT2015-70780-C4-2 and MAT2015-70780-C4-3, the Regional Government of Madrid through the program MULTIMAT-CHALLENGE, ref. S2013/MIT-2862. Dr. J.J.Roa would like to thank the "Juan de la Cierva" Programme for its financial support (grant number: $\mathrm{JCl}-2012-14454)$. 


\section{References}

[1] Alvaredo P, Mari D, Gordo E. High temperature transformations in a steel-TiCN cermet. International Journal of Refractory Metals and Hard Materials. 2013;41:115-20.

[2] Gómez B, Jiménez-Suarez A, Gordo E. Oxidation and tribological behaviour of an Fe-based MMC reinforced with TiCN particles. International Journal of Refractory Metals and Hard Materials. 2009;27:360-6.

[3] Alvaredo P, Abajo C, Tsipas SA, Gordo E. Influence of heat treatment on the high temperature oxidation mechanisms of an Fe-TiCN cermet. Journal of Alloys and Compounds. 2014;591:72-9.

[4] Chicardi E, Torres Y, Sayagués MJ, Medri V, Melandri C, Córdoba JM, et al. Toughening of complete solid solution cermets by graphite addition. Chemical Engineering Journal. 2015;267:297-305.

[5] $\mathrm{Yu} \mathrm{H}$, Liu Y, Jin Y, Ye J. Effect of secondary carbides addition on the microstructure and mechanical properties of $(\mathrm{Ti}, \mathrm{W}, \mathrm{Mo}, \mathrm{V})(\mathrm{C}, \mathrm{N})$-based cermets. International Journal of Refractory Metals and Hard Materials. 2011;29:586-90.

[6] Jung J, Kang S. Effect of ultra-fine powders on the microstructure of $\mathrm{Ti}(\mathrm{CN})-\mathrm{xWC}-\mathrm{Ni}$ cermets. Acta Materialia. 2004;52:1379-86.

[7] Andersson JO, Helander T, Höglund L, Shi P, Sundman B. Thermo-Calc \&amp; DICTRA, computational tools for materials science. Calphad. 2002;26:273-312.

[8] Eustathopoulus N. NMG, Drevet B. Wettability at high temperatures: Pergamon Materials Series; 1999.

[9] Oliver W. C. PGM. Measurement of hardness and elastic modulus by instrumented indentation: Advances in understanding and refinements to methodology. Journal of Materials Research. 2004;19:3-20.

[10] Oliver W.C. PGM. An improved technique for determining hardness and elastic modulus using load and displacement sensing indentation experiments. Journal of Materials Research. 1992;7:1564-83.

[11] C.A.Botero EJ-P, R. Martín, T. Kulkarni, V.K. Sarin, L. Llanes. Nanoindentation and nanoscratch properties of mullite-based environmental barrier coatings: Influence of chemical composition - Al/Si ratio. Surface and Coatings Technology. 2012;239:49-57.

[12] P. Alvaredo MD, B. Ferrari, E. Gordo. . Interface study for the design of alternative matrixes in cermets. EuroPM2015 International Powder Metalurgy Congress \& Exhibition Reims (France): EPMA European Powder Metallurgy Association 2015.

[13] A.Nino AT, S.Sugiyama, H.Taimatsu. Indentation Size Effect for the Hardness of Refractory Carbides Materials Transactions. 2010:1621-6. 
Table 1. Hardness (determined from the hardness average for the displacement interval ranged between $100-1000 \mathrm{~nm}$ ) and elastic modulus (at $200 \mathrm{~nm}$ ) for the TiCN substrate and each metal liquid sample.

\begin{tabular}{|c|c|c|}
\hline Sample & Hardness, $\mathbf{H}$ (GPa) & Elastic modulus, E (GPa) \\
\hline $\mathrm{TiCN}$ & $19.17 \pm 1.19$ & $354 \pm 86$ \\
\hline $\mathrm{Fe}$ & $2.25 \pm 0.18$ & $204 \pm 5$ \\
\hline $\mathrm{Fe}-\mathrm{Mo}_{2} \mathrm{C}$ & $9.27 \pm 0.39$ & $203 \pm 34$ \\
\hline $\mathrm{Fe}-\mathrm{WC}$ & $3.17 \pm 0.19$ & $212 \pm 27$ \\
\hline
\end{tabular}




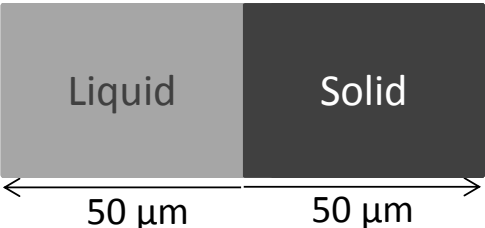

Figure 11. Scheme of the system designed for the simulation of the diffusion (at the interface) between the liquid metallic sample and the solid ceramic substrate. 

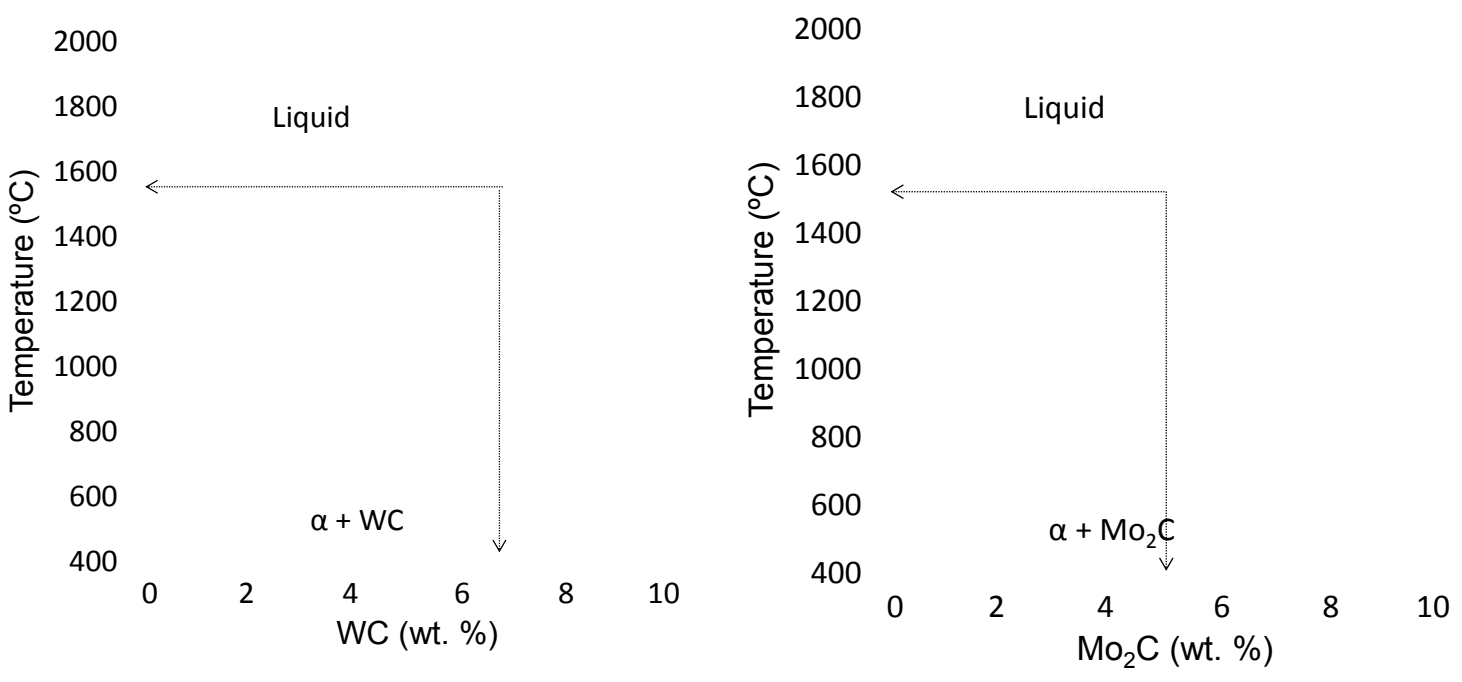

Figure 12. Binary phase diagrams of Fe-WC (left) and $\mathrm{Fe}-\mathrm{Mo}_{2} \mathrm{C}$ (right), calculated by Thermocalc software. 


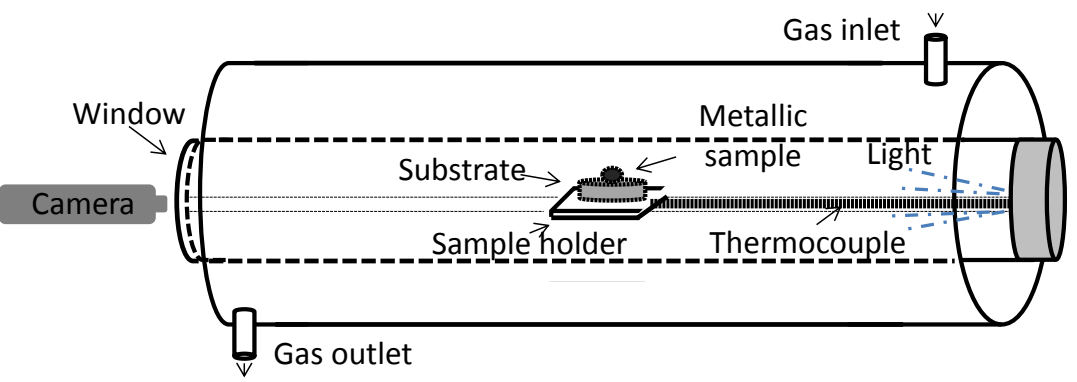

Figure 13. Scheme of the high temperature contact angle measurement equipment. 


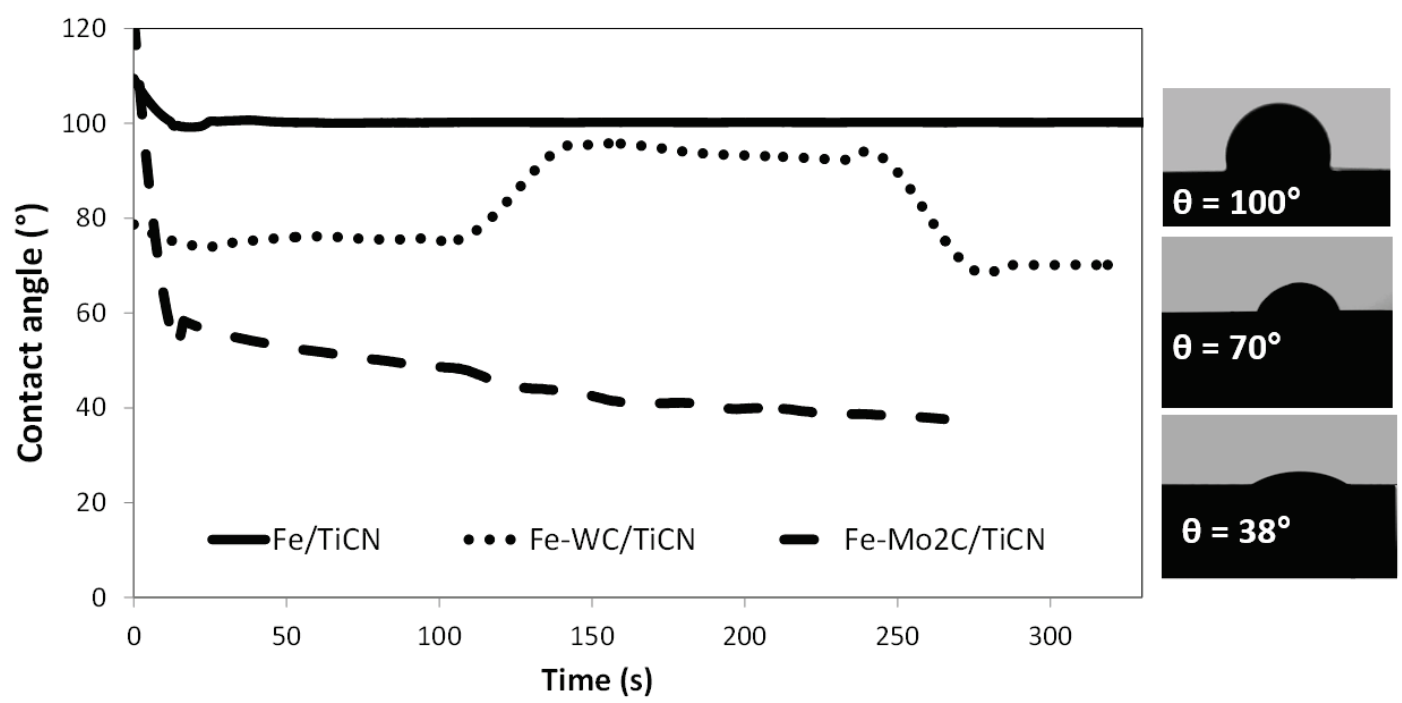

Figure 14. Evolution of contact angle regarding time of the metal/substrate systems: Fe/TiCN; Fe6.2WC/TiCN and $\mathrm{Fe}-5.1 \mathrm{Mo}_{2} \mathrm{C} / \mathrm{TiCN}$ 


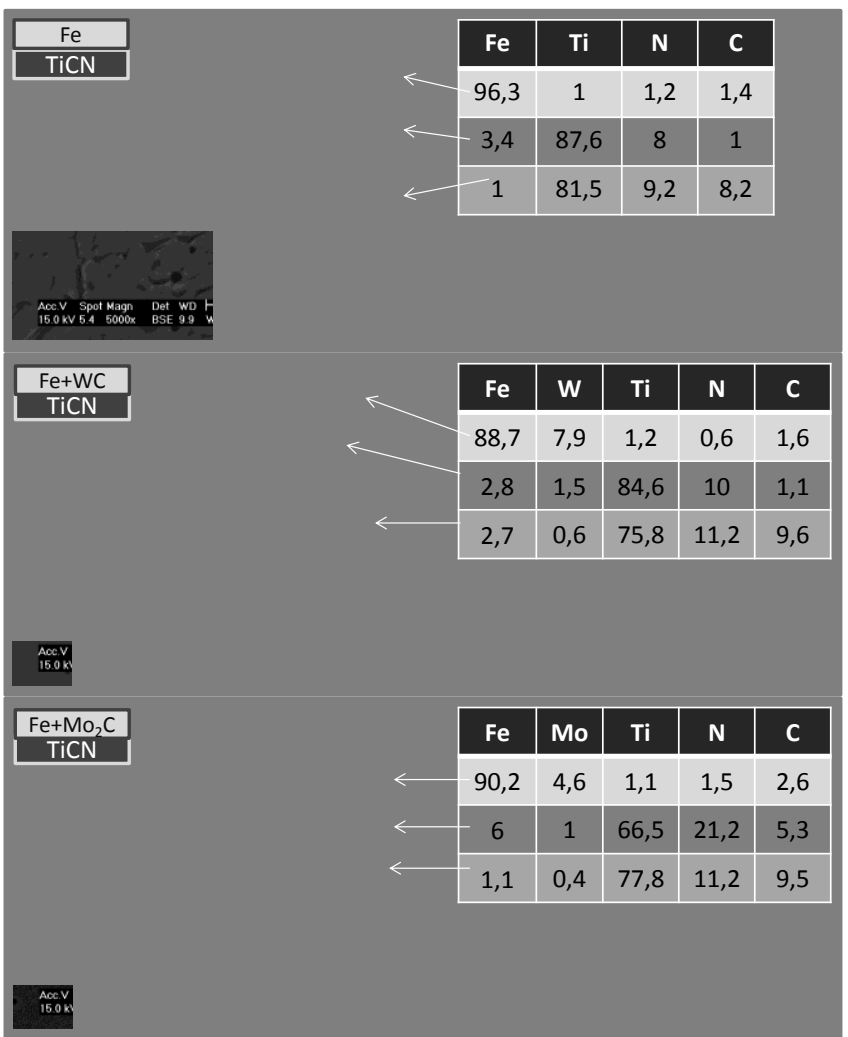

Figure 15. Interface of the systems (left side): Fe/TiCN; Fe-6.2WC/TiCN and Fe-4.8Mo $2 \mathrm{C} / \mathrm{TiCN}$ after wetting experiments and EDX analysis of metallic sample, interface and TiCN substrate (right side). (All the compositions are expressed in wt. \%). 

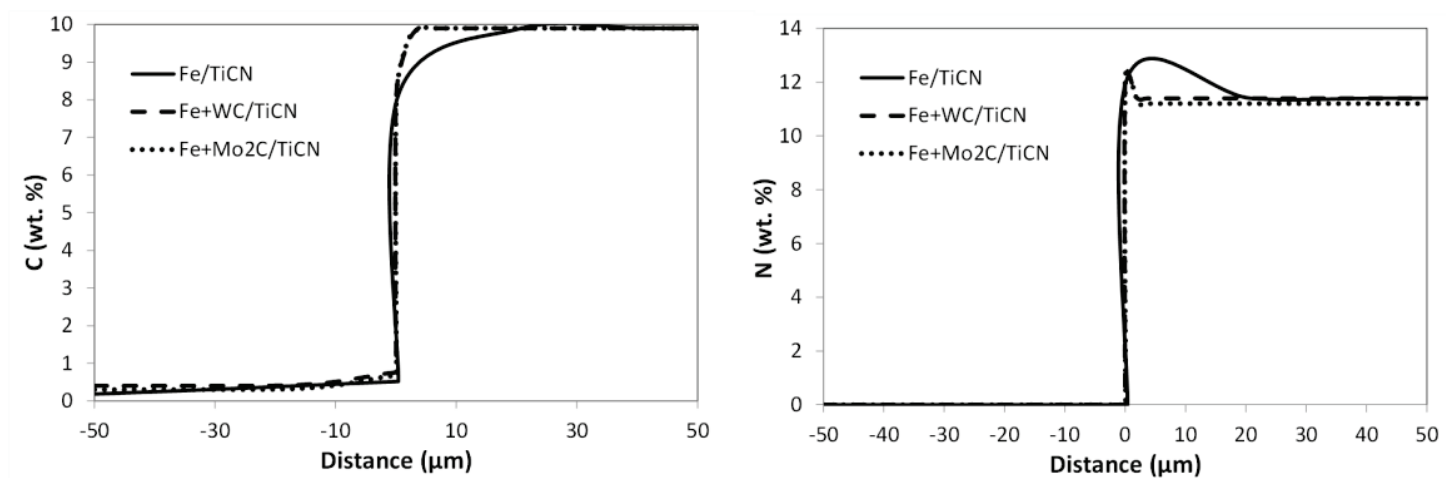

Figure 16. Evolution of the $\mathrm{C}$ and $\mathrm{N}$ wt. \% at the interface for the systems $\mathrm{Fe} / \mathrm{TiCN} ; \mathrm{Fe}-6.6 \mathrm{WC} / \mathrm{TiCN}$ and $\mathrm{Fe}-5.1 \mathrm{Mo}_{2} \mathrm{C} / \mathrm{TiCN}$ simulated by Dictra software (at $1560{ }^{\circ} \mathrm{C}$ in a distance of $100 \mu \mathrm{m}$ during $300 \mathrm{~s}$ ). 

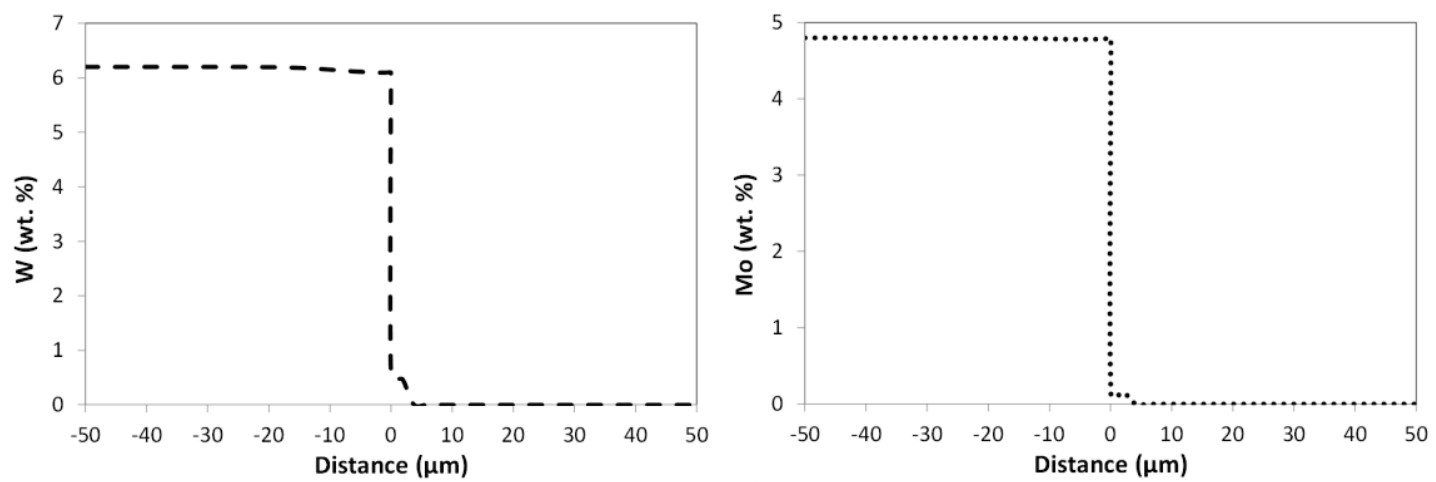

Figure 17. Evolution of the $\mathrm{W}$ and Mo wt. \% at the interface of the systems $\mathrm{Fe}-6.6 \mathrm{WC} / \mathrm{TiCN}$ and $\mathrm{Fe}-$ $5.1 \mathrm{Mo}_{2} \mathrm{C} / \mathrm{TiCN}$, respectively, simulated by Dictra software (at $1560{ }^{\circ} \mathrm{C}$ in a distance of $100 \mu \mathrm{m}$ during 300 s). 


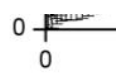

Figure 18. Hardness evolution for all the systems of study against the maximum displacement into surface. 
$\mathrm{Fe}-\mathrm{Mo}_{2} \mathrm{C}$

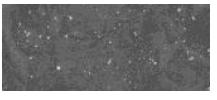

$10 \mu \mathrm{m}$

Figure 19. FESEM image of a residual imprint performed at $1000 \mathrm{~nm}$ of maximum displacement into surface for $\mathrm{Fe}$ and $\mathrm{Fe}-\mathrm{Mo}_{2} \mathrm{C}$ metallic systems. 


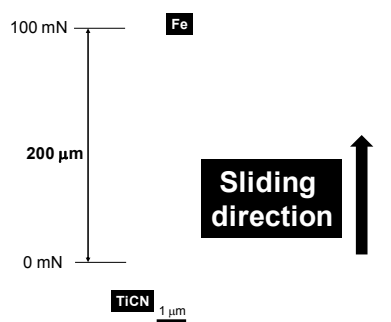

Figure 20. FESEM image for the nanoscratch track performed at incremental load from 0 to $100 \frac{5 \mu \mathrm{m}}{\mathrm{mN}}$ (left hand side) for the Fe/TiCN system. Magnification of the main fracture events activated in the interface for all the systems investigated here done at constant load $(100 \mathrm{mN})$. 
Highlights

- WC and $\mathrm{Mo}_{2} \mathrm{C}$ influence on $\mathrm{Fe} / \mathrm{TiCN}$ interface formation, composition and properties

- Chemical and mechanical characterization using different complementary techniques

- Results obtained are the basis to tailor new metallic binders for cermets 